\title{
Tree Vitality Assessment in Urban Landscapes
}

\author{
David Callow $^{1}$, Peter May ${ }^{2}$ and Denise M. Johnstone ${ }^{3, *}$ \\ 1 Urban Forest \& Ecology, City of Melbourne, Melbourne VIC 3000, Australia; \\ david.callow@melbourne.vic.gov.au \\ 2 School of Ecosystem and Forest Sciences, Burnley Campus, University of Melbourne, \\ Richmond VIC 3121, Australia; pmay@unimelb.edu.au \\ 3 School of Ecosystem and Forest Sciences, Parkville Campus, University of Melbourne, \\ Parkville VIC 3010, Australia; denisej@unimelb.edu.au \\ * Correspondence: denisej@unimelb.edu.au; Tel.: +61-427-689-495
}

Received: 28 March 2018; Accepted: 16 May 2018; Published: 21 May 2018

check for updates

\begin{abstract}
The recent prolonged drought in Melbourne, Australia has had a deleterious effect on the urban forest, resulting in the premature decline of many mature trees and a consequent decline in the environmental services that trees are able to provide to urban residents. Measuring the severity of tree stress and defoliation due to various climatic factors is essential to the ongoing delivery of environmental services such as shade and carbon sequestration. This study evaluates two methods to assess the vitality of drought stressed Elm trees within an inner-city environment—bark chlorophyll fluorescence measured on large branches and an urban visual vitality index. Study species were Ulmus procera Salisb. (English Elm) and Ulmus $\times$ hollandica (Dutch Elm), which are important character and shade tree species for Melbourne. Relationships were identified between leaf water potential and the urban visual vitality index and between leaf water potential and bark chlorophyll fluorescence measured on large branches, indicating that these methods could be used to assess the effect of long-term drought and other stressors on urban trees.
\end{abstract}

Keywords: urban tree growth; climate change; drought stress

\section{Introduction}

The recent prolonged drought in Melbourne, Australia (1997-2010) has had a deleterious effect on many trees within the urban forest. Within the City of Melbourne (a municipality of $37.7 \mathrm{~km}^{2}$ around the Melbourne CBD), prolonged drought and resulting mandatory changes to irrigation practices have led to a premature loss of vitality in many mature trees. Climate-related tree decline within the City of Melbourne was particularly evident in exotic deciduous trees, such as Ulmus spp., which are widely planted throughout the City of Melbourne and are recognized as an important element of the city landscape [1].

Tree vitality can be defined in relation to the plant response to physiological stress [2]. Very low vitality trees will not respond to treatment to ameliorate physiological stress, but will remain in a depleted state or die, possibly because of extremely low carbohydrate reserves. High vitality trees, on the other hand, will respond and recover from drought or other physiological stressors.

Chlorophyll fluorescence measurements and in particular ratios of $F_{\mathrm{v}} / \mathrm{F}_{\mathrm{m}}$ are used to examine aspects of plant photosynthetic and photochemical processes that give rise to plant vitality [3]. However, most chlorophyll fluorescence and many other physiological measurements of plant stress utilize leaf material, which precludes the year-round assessment of deciduous trees and can confound tree vitality with the health of individual leaves [4]. Using chlorophyll fluorescence measurements in bark tissue to assess vitality, though possible, has seldom been used in practice [4]. The most commonly used chlorophyll fluorescence measurement is $F_{v} / F_{m}$, where $F_{v}$ is the difference between maximum 
$\left(\mathrm{F}_{\mathrm{m}}\right)$ and minimum $\left(\mathrm{F}_{0}\right)$ fluorescence [5]. $\mathrm{F}_{\mathrm{v}} / \mathrm{F}_{\mathrm{m}}$ is the theoretical measure of the quantum efficiency of photosystem two (PSII) during photosynthesis if all the PSII reaction centers are open. A decrease in the chlorophyll fluorescence parameter $F_{v} / F_{m}$ indicates photoinhibitory damage. $F_{v} / F_{m}$ values can decrease significantly with salt, heat, and herbicide damage [3], as well as with drought stress [6]. Leaf $\mathrm{F}_{\mathrm{v}} / \mathrm{F}_{\mathrm{m}}$ values between 0.78 to 0.85 are typical for healthy, non-stressed trees [3]; however, bark values are typically lower, probably due to a decreased efficiency in bark chlorenchyms and an external bark layer that may inhibit the fluorescence signal passing to the measurement instrument [4].

Visual methods for the assessment of tree vitality have been successfully applied in natural forest stands [7,8], hardwood plantations [4], and urban environments [9,10]. A numerical crown assessment technique was developed for living Eucalyptus (Corymbia) maculata (Hook.) K.D. Hill \& L.A.S. Johnson (spotted gum), Eucalyptus fibrosa F. Muell. (ironbark) and E. drepanophylla F. Muell ex Benth (syn. E. cerebra F. Muell) trees by Grimes [7]. The method used crown position in relation to other trees, crown size, crown density, the number of dead branches, and epicormic growth and developed a prediction equation for how well these factors explained incremental growth at breast height. He found that each of the five variables contributed significantly to a prediction equation for incremental growth, but that for the best results, factors should be weighted differently, for example, epicormic growth on a three-point scale and crown density on a nine-point scale. Martin et al. [8] used the above method by Grimes [7] to develop a visual assessment method to examine the spatial representation of eucalypt dieback across two sites in a natural forest stand. At one site, they identified a positive relationship between vitality and tree size. Aiming to assess the vitality of drought stressed and declining mature trees, Johnstone et al. [4] adapted the method described by Martin et al. [8] for a study in plantation eucalypts and found correlations between visual vitality and total leaf area, above ground biomass, leaf chlorophyll fluorescence (summer), and trunk bark chlorophyll fluorescence (spring, summer, and autumn).

A more detailed discussion of methods to assess long-term drought and/or vitality in trees can be found in Johnstone et al. [2]. In this paper, the authors discuss the relative merits of measuring tree vitality using tree growth and visual parameters; leaf or needle morphology and biochemistry; canopy transparency and reflectance; electrical admittance/impedance; gaseous exchange; and chlorophyll fluorescence.

We report here on how we have used an urban visual vitality index and bark chlorophyll fluorescence measured on large branches to predict drought stress in mature urban trees. Specifically, we tested if there was a relationship between the drought stress in Ulmus procera Salisb. (English Elm) and Ulmus $\times$ hollandica (Dutch Elm) and urban visual vitality index values and/or bark chlorophyll fluorescence measurements on large branches. Our results inform management decisions for trees in urban environments for the benefit of city dwellers and users by maximizing canopy cover for the successful provision of environmental services. The results also help tree managers provide measures for the successful establishment of succession planning for tree replacement.

\section{Materials and Methods}

For this study, trees were examined around the central business district of the City of Melbourne, Australia (Latitude $37^{\circ} 47^{\prime} \mathrm{S}$, longitude $144^{\circ} 58^{\prime} \mathrm{E}$ ). Melbourne has had an average annual rainfall of $648 \mathrm{~mm}$ and high summer temperatures with a January mean maximum of 26 degrees Celsius from 1855 to 2015 [11]. The experimental trees consisted of six mature Ulmus procera located in a suburban streetscape in a contiguous row and 32 randomly selected Ulmus $\times$ hollandica located within inner city parks from two avenues. All trees displayed visual drought stress symptoms and displayed variation in crown condition from very stressed to not particularly stressed, to properly evaluate the relationship between drought stress and the two assessment methods.

The urban visual vitality index used (Figure 1) was adapted from a method described by Johnstone et al. [4]. The urban visual vitality index had three criteria: crown size, crown density, and crown epicormic growth. Each of the criteria was scored numerically; 1 to 5 (crown size), 1-9 (crown density), 
and 1-3 (crown epicormic growth). The relative weighting of each parameter follows Grimes [6] who, as previously stated, developed a predictive equation for how well each factor explained incremental growth at breast height. The score was totaled, with a higher score indicating greater vitality (Figure 1). Urban visual vitality index assessments were undertaken on all trees in December 2010, January 2011, and February 2011. The lowest score in December was 3.5 and the highest was 14.5 out of a possible 17 , confirming the range of tree crown conditions mentioned above.
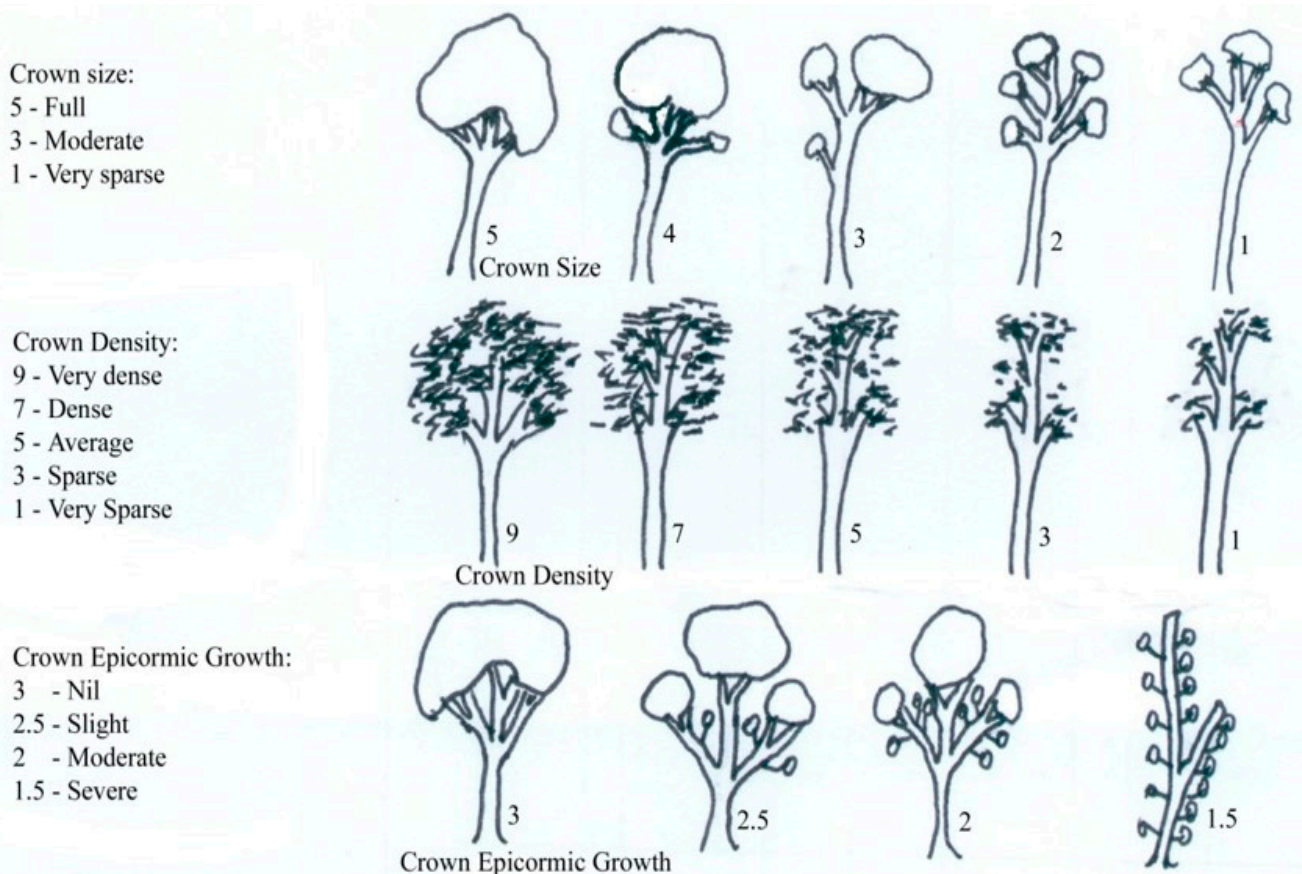

Figure 1. Diagrammatic representation of the assessment of urban visual vitality index for mature trees (after $[4,7,8,12])$.

Leaf water potential was measured in March 2011 by harvesting five fully expanded sun leaves from within the upper half of the crown of each tree. Leaves were collected using an Elevating Work Platform. For pre-dawn measurements, leaves were collected between 5:30 and 7:00 a.m., prior to direct sunlight reaching any part of the canopy on consecutive days with similar weather conditions. For midday measurements, leaves were collected between 12:00 p.m. and 1:30 p.m. also on consecutive days with similar weather conditions. Water potential readings were undertaken in a PMS Model 1000 pressure chamber (PMS instrument company, Albany, OR, USA) within 20 min of leaf harvesting. Leaf water potential was measured using the protocol first described by Scholander [13].

Bark chlorophyll fluorescence was also measured in March 2011 with a Hansatech-Handy Plant Efficiency Analyzer (Handy PEA, Hansatech Instruments, King's Lynn, Norfolk, UK). Bark chlorophyll fluorescence was measured by attaching a collar containing 10 apertures (modified leaf clips) as described in Johnstone et al. [4]. The apertures were $35 \mathrm{~mm}$ apart and the branches were third order branches approximately $15 \mathrm{~cm}$ in diameter, accessed by an Elevating Work Platform. The apertures were also closed for 30 min until a steady state was achieved.

Once the darkening period was complete, a red light was then flashed (modulated) onto the bark surface with the Handy PEA and an increase in the yield of chlorophyll fluorescence occurred over $1 \mathrm{~s}$ (induction curve), until the PS II reaction centers progressively closed [5]. Values for each tree were averaged for the 10 readings. Readings well outside a normal range were eliminated from the data set.

Simple linear regression analysis was undertaken with Minitab 17 software to identify relationships between assessment techniques and between species. 


\section{Results}

Statistical relationships were observed between the February urban visual vitality index and midday leaf water potential $\left(p<0.000, r^{2}=0.462, n=38\right.$ ) (Figure $2 \mathrm{a}$ ) and branch bark $\mathrm{F}_{\mathrm{v}} / \mathrm{F}_{\mathrm{m}}$ fluorescence and pre-dawn leaf water potential $\left(p<0.001, r^{2}=0.454, n=22\right)$ (Figure 2b) when all results were pooled. Elms with lower visual vitality indices had decreased water potentials and elms with lower branch bark $\mathrm{F}_{\mathrm{v}} / \mathrm{F}_{\mathrm{m}}$ fluorescence also had decreased water potentials.

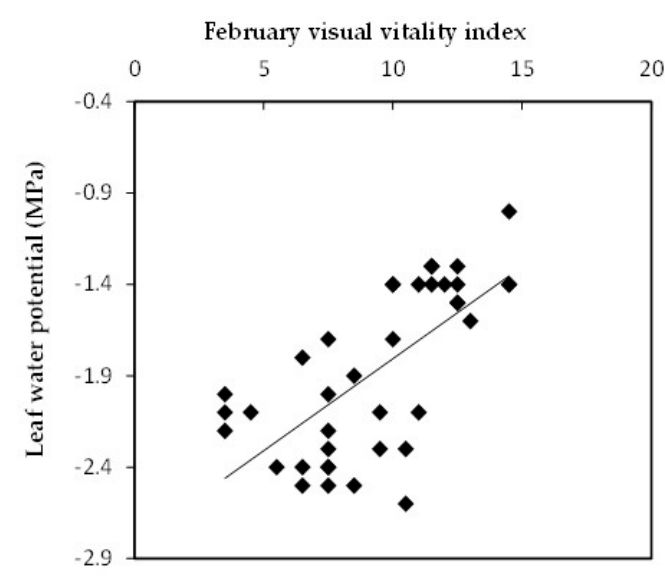

(a)

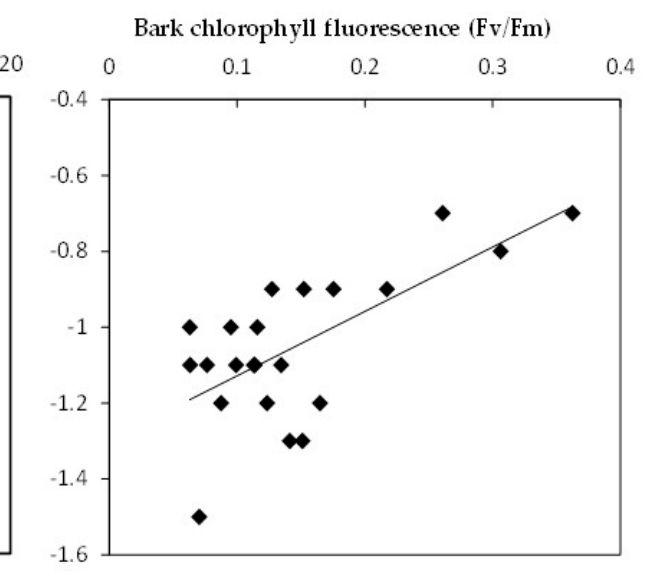

(b)

Figure 2. (a) Ulmus spp. midday leaf water potential (MPa) versus February Urban Visual Vitality Index $\left(p<0.000, r^{2}=0.462, n=38\right)$; (b) Ulmus spp. pre-dawn leaf water potential (MPa) versus branch bark chlorophyll fluorescence $\left(\mathrm{F}_{\mathrm{v}} / \mathrm{F}_{\mathrm{m}}\right)$ and $\left(p<0.001, r^{2}=0.454, n=22\right)$.

There were strong individual species differences between the two Ulmus species and the measured relationships in this study (Table 1). Statistical relationships were observed between the February urban visual vitality index and midday leaf water potential for Ulmus $\times$ hollandica, but not for Ulmus procera (Table 1). Similarly, statistical relationships were observed between branch bark $F_{v} / F_{m}$ fluorescence and pre-dawn leaf water potential in Ulmus $\times$ hollandica, but again not for Ulmus procera (Table 1). 
Table 1. Summarised results from basic statistics and simple linear regression analyses comparing pre-dawn water potentials with the urban visual vitality index and midday water potentials with branch bark $\mathrm{F}_{\mathrm{v}} \mathrm{F}_{\mathrm{m}}$ in both Ulmus $\times$ hollandica and Ulmus procera.

\begin{tabular}{|c|c|c|c|c|c|c|c|c|c|c|c|}
\hline \multirow{2}{*}{$\begin{array}{c}\text { Statistical Value } \\
\text { Comparisons }\end{array}$} & \multirow{2}{*}{$N$} & \multicolumn{2}{|c|}{ Mean } & \multicolumn{2}{|c|}{ Minimum } & \multicolumn{2}{|c|}{ Maximum } & \multicolumn{2}{|c|}{ SD Value } & \multicolumn{2}{|c|}{ Regression Statistics } \\
\hline & & UVVI & MDWP & UVVI & MDWP & UVVI & MDWP & UVVI & MDWP & $p$ & $r^{2}$ \\
\hline U. hollandica; uvvi v mdwp & 32 & 9.7 & -1.82 & 3.5 & -2.5 & 14.5 & -1.0 & 3.225 & 0.454 & $<0.000^{a}$ & 0.528 \\
\hline U. procera; uvvi v mdwp & 6 & 7.3 & -2.07 & 6.5 & -2.5 & 8.5 & -1.7 & 0.753 & 0.350 & 0.629 & 0.064 \\
\hline Ulmus data; uvvi v mdwp & 38 & 9.3 & -1.87 & 3.5 & -2.6 & 14.5 & -1.0 & 3.092 & 0.458 & $<0.000^{a}$ & 0.462 \\
\hline Comparisons & & $\mathrm{BB} \mathrm{F}_{\mathrm{V}} / \mathrm{F}_{\mathrm{M}}$ & PDWP & $\mathrm{BB} \mathrm{F}_{\mathrm{V}} / \mathrm{F}_{\mathrm{M}}$ & PDWP & $\mathrm{BB} \mathrm{F}_{\mathrm{V}} / \mathrm{F}_{\mathrm{M}}$ & PDWP & $\mathrm{BB} \mathrm{F}_{\mathrm{V}} / \mathrm{F}_{\mathrm{M}}$ & PDWP & & \\
\hline U. hollandica; $\mathrm{bb} \mathrm{F}_{\mathrm{V}} / \mathrm{F}_{\mathrm{M}} \mathrm{v} \mathrm{pdwp}$ & 16 & 0.149 & -1.03 & 0.063 & -1.5 & 0.363 & -0.7 & 0.091 & 0.212 & $<0.001^{a}$ & 0.569 \\
\hline Ulmus data; bb $\mathrm{F}_{\mathrm{V}} / \mathrm{F}_{\mathrm{M}} \mathrm{v} \mathrm{pdwp}$ & 22 & 0.146 & -1.05 & 0.061 & -1.5 & 0.363 & -0.7 & 0.078 & 0.197 & $<0.001^{\mathrm{a}}$ & 0.454 \\
\hline
\end{tabular}

a Statistical relationship is significant and positive; $N=$ number of samples; $\mathrm{UVVI}=$ urban visual vitality index; $\mathrm{MDWP}=$ midday water potential; $\mathrm{BB} \mathrm{F}_{\mathrm{V}} / \mathrm{F}_{\mathrm{M}}=\mathrm{branch}$ bark $\mathrm{F}_{\mathrm{V}} / \mathrm{F}_{\mathrm{M}}$; $\mathrm{PDWP}=$ pre-dawn water potential; SD value = the standard deviation of a group of variables; $p=$ probability for the $t$ test that the coefficient of the independent variable is equal to zero; $r^{2}=$ variation in the dependent variable that can be explained by the urban visual vitality index or branch bark $\mathrm{F}_{\mathrm{v}} \mathrm{F}_{\mathrm{m}}$ data. 


\section{Discussion}

This study aimed to test practical methods to predict tree stress, particularly long-term moisture stress. The average value for pre-dawn water potential in this study for elms was $-1.0 \mathrm{MPa}$. This indicates that the elms were moderately stressed [14,15]. However, most of the elms had been experiencing moderate to severe drought stress over a significant period, as evidenced by their low urban visual vitality indices. The average score for the elm urban visual vitality index was nine out of a possible 17. The regression analysis of the elm data indicates that the urban visual vitality index used in this study can be used to predict decreased midday leaf water potential in elm populations and in particular within the species Ulmus $\times$ hollandica (Figure 2a; Table 1). There were, however, no statistical relationships observed between the February urban visual vitality index and midday leaf water potential in Ulmus procera when the six trees of this species were analyzed separately (Table 1). This can be explained by the very low variability in the February visual vitality and midday water potential data in Ulmus procera (Table 1). It is also a function of the very low number of samples for this species. The pooled Elm results suggest that the urban visual vitality index could be used as an indication of drought stress in mature elms in Summer through visual means and without the need for specialized equipment.

There were no statistical relationships observed between branch bark $F_{v} / F_{m}$ fluorescence and pre-dawn leaf water potential in Ulmus procera when the six trees of this species were analyzed separately (Table 1). This can be explained by the very low variability visible in branch bark $F_{v} / F_{m}$ fluorescence and pre-dawn leaf water potential data in Ulmus procera (Table 1). The lack of a relationship could again be a function of the very low number of samples for this species. But again, when all Elm results were pooled or Ulmus $\times$ hollandica was examined separately, bark chlorophyll fluorescence testing on large branches could predict pre-dawn water status, suggesting that this technique could also be used to assess drought stress in mature elms (Figure 2b; Table 1). Branch bark chlorophyll fluorescence would theoretically enable the year-round testing of deciduous trees, unlike techniques that require leaf samples. Evidence from a previous study on Eucalyptus globulus suggests that bark chlorophyll fluorescence may correlate with longer term vitality, whereas leaf chlorophyll fluorescence may be dependent on the health of individual leaves [4].

Under existing and predicted impacts of climate change, it is likely that globally, trees within many urban environments will be subject to altered growing conditions [16]. The ability of trees to adapt to these changing environments will vary; however, trees that have low vitality or that are nearing the end of their lifespan are likely to be less tolerant to change. Identifying suitable assessment techniques for monitoring the vitality of drought stressed mature urban trees will provide tree managers with additional resources for maintaining valuable mature tree resources.

\section{Conclusions}

We found relationships between the Elm urban visual vitality index and water status and between Elm branch bark fluorescence and leaf water potential, suggesting that both methods can be effectively used for the assessment of long-term drought stress in mature trees. Branch bark fluorescence may be used as an assessment tool even when trees have no leaves in winter and is not dependent on the health of individual leaves. The urban visual vitality index and branch bark fluorescence can aid in the assessment of canopy cover-an essential part of environmental service provision.

Author Contributions: D.C., P.M., and D.M.J. conceived and designed the experiments; D.C. and D.M.J. performed the experiments; D.C. and D.M.J. analyzed the data; D.C. and D.M.J. wrote the paper.

Acknowledgments: The in-kind support of the City of Melbourne, Australia during this research is gratefully acknowledged. The authors also wish to thank Patricio Sepulveda for assistance with field work, and Gerd Bossinger and Ian Woodrow for their preliminary review of this manuscript.

Conflicts of Interest: The authors declare no conflict of interest. The founding sponsors had no role in the design of the study; in the collection, analyses, or interpretation of data; in the writing of the manuscript, and in the decision to publish the results. 


\section{References}

1. May, P.; Livesley, S.; Shears, I. Managing and monitoring tree health and soil water status during extreme drought in Melbourne, Victoria. Arboricult. Urban For. 2013, 39, 136-145.

2. Johnstone, D.; Moore, G.; Tausz, M.; Nicolas, M. The measurement of plant vitality in landscape trees. Arboricult. J. 2013, 35, 18-17. [CrossRef]

3. Percival, G. The use of chlorophyll fluorescence to identify chemical and environmental stress in leaf tissue of three oak (Quercus) species. J. Arboricult. 2005, 31, 215-227.

4. Johnstone, D.; Tausz, M.; Moore, G.; Nicolas, M. Chlorophyll fluorescence of the trunk rather than leaves indicates visual vitality in Eucalyptus saligna. Trees-Struct. Funct. 2012, 26, 1565-1576. [CrossRef]

5. Maxwell, K.; Johnson, G.N. Chlorophyll fluorescence-A practical guide. J. Exp. Bot. 2000, 51, 659-668. [CrossRef] [PubMed]

6. Percival, G.; Sheriffs, C. Identification of drought-tolerant woody perennials using chlorophyll fluorescence. J. Arboricult. 2002, 28, 215-223.

7. Grimes, R. Crown Assessment of Natural Spotted Gum (Eucalyptus maculata), Ironbark (Eucalyptus fibrosa, Eucalyptus drepanophylla) Forest; Dept. of Forestry: Brisbane, Australia, 1978.

8. Martin, R.A.U.; Burgman, M.A.; Minchin, P.R. Spatial analysis of eucalypt dieback at Coranderrk, Australia. Appl. Veg. Sci. 2001, 4, 257-266. [CrossRef]

9. Fite, K. Impacts of Root Invigoration (tm) and Its Individual Components on the Performance of Red Maple (Acer rubrum). Ph.D. Thesis, Clemson University, Clemson, SC, USA, 2008.

10. Martinez-Trinidad, T.; Watson, W.T.; Arnold, M.A.; Lombardini, L.; Appel, D.N. Comparing various techniques to measure tree vitality of live oaks. Urban For. Urban Green. 2010, 9, 199-203. [CrossRef]

11. Bureau of Metrology Commonwealth of Australia. Available online: http://www.bom.gov.au/ (accessed on 25 April 2018).

12. Lindenmayer, D.B.; Norton, T.W.; Tanton, M.T. Differences between wildfire and clearfelling on the structure of montane ash forests of Victoria and their implications for fauna dependent on tree hollows. Aust. For. 1990, 53, 61-68. [CrossRef]

13. Scholander, P.F.; Hammel, H.; Hemmingsen, E.; Bradstreet, E. Hydrostatic pressure and osmotic potential in leaves of mangroves and some other plants. Proc. Natl. Acad. Sci. USA 1964, 52, 119-125. [CrossRef] [PubMed]

14. Ranney, T.G.; Whitlow, T.H.; Bassuk, N.L. Response of five temperate deciduous tree species to water stress. Tree Physiol. 1990, 6, 439-448. [CrossRef] [PubMed]

15. Walters, M.B.; Reich, P.B. Response of Ulmus americana seedlings to varying nitrogen and water status. 1 photosynthesis and growth. Tree Physiol. 1989, 5, 159-172. [CrossRef] [PubMed]

16. Allen, C.; Macalady, A.; Chenchouni, H.; Bachelet, D.; McDowell, N.; Vennetier, M.; Kitzberger, T.; Rigling, A.; Breshears, D.; Hogg, E. A global overview of drought and heat-induced tree mortality reveals emerging climate change risks for forests. For. Ecol. Manag. 2010, 259, 660-684. [CrossRef]

(C) 2018 by the authors. Licensee MDPI, Basel, Switzerland. This article is an open access article distributed under the terms and conditions of the Creative Commons Attribution (CC BY) license (http://creativecommons.org/licenses/by/4.0/). 